\title{
The Rhetorical Development of Students' Research Paper Background
}

\author{
Irma Soraya \\ English Language Education Department \\ UIN Sunan Ampel Surabaya \\ Tri Rohmat Sholehuddin \\ English Language Education Department \\ UIN Sunan Ampel Surabaya
}

\author{
Aditya Herwanda Riswan \\ English Language Education Department \\ UIN Sunan Ampel Surabaya \\ Azza Mahendra \\ English Language Education Department \\ UIN Sunan Ampel Surabaya
}

\begin{abstract}
This study is conducted of therhetorical development in research background of the eight semester students of English Language Education Department. The focus of this research obtain students' rhetorical development of research banckground. Most of students have problem in writing their proposal background. They often get a diffuclties in organizing their ideas as their research background. In this research, the research uses qualitative descriptive as the design of his research. Data collection technique uses in this research is table of based on model by Swales. Rhetorical structure model of student's proposal background and to help his analyse the rhetorical problem found in the their background. The research find that the proposal background of the students have some rhetorical problem. The analysis shows that the analysed background have structure of background by Swales. So it can be concluded that students face some rhetorical problem in writing their background.
\end{abstract}

Keywords: rhetorical problem, sructure, proposal background

\section{INTRODUCTION}

As a student in university level, writing academically is one of the undeniable requirements writing ability to is needed by college students to fulfill important, for instance, course assignment, prerequisite competition, professional enhancement, and graduation, therefore, it is crucial students to have good skill in academic writing. Good academic writing (what kind of rough writing such as Well organized, Well described, Accurate features (vocab, grammar. One of the conditions that make academic writing is new is structured. it spelled out from rhetorical steps ( by moving to write it will be like in ex

The students of university a research proposal is very important assignment before they start off writing a thesis. Nelleke states that a research proposal is a planning document that outlines the writer's thinking about a research problem and describes what is to be studied and how

To achieve that purpose, a good research proposal has to follow certain rules. These include the language used.
Grammatical structure, punctuation, the technique of citing, quoting and referencing, the technique of paraphrasing and summarising, and the organization of ideas. In addition, a research proposal as academic writing from other kinds of writing is the organization of ideas and language used. Both of them are related to the rhetorical elements.

To structure these rhetorical elements in writing is not an easy task. The writer should follow some certain steps. Zapotoczny states that students need to work hard to finish research writing. They need help in narrowing down a topic, forming research questions, conducting library searches, writing with focus, and correcting grammar. ( Zapotoczny Walter, How to Write the Introduction to Research Proposal (eHow: Culture \& Society Charities \& Organizations, 2010 ).

There are certain of writing course. The students are taught about how to write an academic writing start from writing an essay up to the writing of research proposal. In conclusion, the academic writing skill of a student can be improved by learning academic writing matters. But in reality, students still find difficulties to start writing a thesis. The researcher assumed that it happens cause they have a problem in writing their research proposal. The researcher wants to analyze the background structure and rhetorical move a problem in students proposal. The researcher has some reasons, as follows:

First, previous research about the rhetorical problem in the background of the research proposal by the previous thesis conducted by Muh. Yusuf. He didn't analyze the rhetorical move. He only analyzes the element aspect of the problem in the research proposal. he only analyzes the element aspect of the problem in the research proposal. Through his study, he found that 46,6 \% percentage of students faced problem in writing an introduction. Therefore the researcher wants to complete the previous research finding in the research proposal problem by doing research which focuses on the rhetorical problem in the background of the research proposal.

Second, the researcher knows that a good background in the research proposal is very important. If the background is not appropriate to the rhetorical background features, the research will be difficult to understand by the readers. Therefore this research is important to do because 


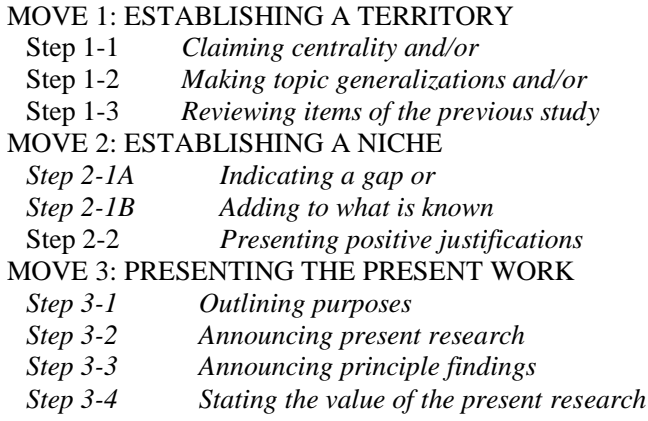

\section{(c) Previous Study}

Introduction section in an academic research writing is important part since it should attract the reader. Recently, there has been considerable interest among researchers in analysing the generic structure, discourse features, and history of such publication. the work of Swales on article introductions is considered a pioneer of genre analysis. He proposed a system of analysis which categorizes the discourse units found in the introduction section of research articles into three communicative moves and his system of analysis is often called "move analysis". Swales model is also calles as Create a Research Space (CARS).

So through this study, the researcher wants to analyse the rhetoric in research proposal background use CARS model. The researcher hopes from this research, it can complete the previous study.

\section{METHOD}

In this study, the researcher is the key instrument and as the someone who collects the data. To analyse the data, the researcher used theories to support the research instrument. The theories used in this research are CARS Model by Swales Then, to analyse the data, the researcher used Wallwork's theory about the useful phrases in research writing. These theories support the reseracher in collecting the data.

This study is conducted in English Language Education Department at Faculty of Education and Teacher Training, UIN Sunan Ampel Surabaya. It is located in Jl. A.Yani 117 Surabaya. The subject of this study is the research proposal background of the eight semester students of English Language Education Department

There is one main data to answer two questions in this research. So there is just one main data in this research because they can not be separated. The researcher uses the adapted Swales' theory of CARS model to analyse the moves of the background to know their schematic structures. Because the research focuses on analysing the rhetoric in research proposal background, this data completed the research finding because through this research the researcher know the rhetorical schematic structure of research proposal background.

In case of collecting data of the research, it totally needs an instrument. Thus, the researcher designs the instruments for investigating research questions by adapting from the theory It is atable of checklist which can be used to analyse 
rhetorical shematic structure in research proposal background.

Data analysis technique is data collected by techniques of conducting document study of the research proposal background of the eighth semester students of English Teacher Education Department The first research question is The note of rhetorical schematic structure was based on the signal phrases of background moves as suggested by Wallwork

\section{FINDINGS AND DISCUSSION}

Based on the data expresssion used in the Proposal background of the eight semester students (see appendix 1) shows rhetorical schematic structure model in each background. It also shows some rhetorical problem in their Proposal background. the table consits of 2 column, the first column is the Proposal number (10 analysed background) then the second is the schematic structure of each Proposal. The number in second column symbolized steps used in the analysed background.

\section{Move 1 - Establishing the Territory}

\begin{tabular}{|l|l|l|}
\hline \multirow{4}{*}{ Move } & \multirow{2}{*}{ Steps } & Proposal Background \\
\cline { 3 - 3 } & $\begin{array}{l}\text { Number of step move } \\
\text { in Proposal }\end{array}$ \\
\hline \multirow{4}{*}{1} & 1 & 22 \\
\cline { 2 - 3 } & 2 & 14 \\
\cline { 2 - 3 } & 3 & 15 \\
\cline { 2 - 3 } & Other & 2 \\
\hline
\end{tabular}

Out of the 10 analysed background, all backgrounds contain move 1 , moreover all the introductions start with move 1 as well. Step 1 is the most frequently used in the 10 analysed background. From the examples above it can be shown that out of three from the ten writers in their Proposal background use the word important and most to claim that the topic under investigation is important for his or her own research.

Move 2 - Establishing a Niche

\begin{tabular}{|l|l|l|}
\hline \multirow{4}{*}{ Move } & \multirow{2}{*}{ Steps } & Proposal Background \\
\cline { 3 - 3 } & & $\begin{array}{l}\text { Number of step move } \\
\text { in Proposal }\end{array}$ \\
\hline \multirow{3}{*}{2} & $2-1 \mathrm{~A}$ & 5 \\
\cline { 2 - 3 } & $2-1 \mathrm{~B}$ & 9 \\
\cline { 2 - 3 } & $2-2$ & 2 \\
\cline { 2 - 3 } & Other & 10 \\
\hline
\end{tabular}

The data above shows that only 2 expressions is found to signal this step. this step 2 is only found cyclically in Proposal B. It can classify to this step, because the writer present her positive justification to the methosd used by the previous researcher.

Move 3 - Presenting Present Work

\begin{tabular}{|l|l|l|}
\hline \multirow{4}{*}{ Move } & \multirow{2}{*}{ Steps } & $\begin{array}{l}\text { Proposal Background } \\
\text { Number of step move } \\
\text { in Proposal }\end{array}$ \\
\hline \multirow{4}{*}{3} & $3-1$ & 9 \\
\cline { 2 - 3 } & $3-2$ & 8 \\
\cline { 2 - 3 } & $3-3$ & 0 \\
\cline { 2 - 3 } & $3-4$ & 4 \\
\cline { 2 - 3 } & $3-5$ & 0 \\
\cline { 2 - 3 } & Other & 22 \\
\hline
\end{tabular}

From the data above shows that the highest frequency step used in the background is the step other which categorized in this move 3 by the researcher. It can be found in the Proposal all analysed background. this step is used cyclically by the writers in Proposal C, D, E, F, G, H, I, and J.

Since Swales proposes a system of analysis which categorizes the discourse units found in the introduction section of reserach article into three communicative moves (CARS), many study dealing with introduction have been done by using his model. This study also use Swales CARS model as a tool to do this research. The investigation of proposal background proves that Swales model is a good starting point in analysing schematic structure and rhetorical problem.

The researcher agree to Antony's statement that Swales's model is only good at the starting point. She found that there are some steps which is not appropriate to analyse the background of proposal like in the step 3 and 5 in move 3. Announcing principle finding in the proposal background is not common used because there seems to be tendency that proposal writers do not normally announce their finding in the introduction section.

From the analysis result also shows that there is a gap between the theory and the reality. The schematic structure of the analysed backgrounds is quite different from the ideal theory of schematic structure. These differences might be partially influenced by the writers' culture, knowledge, editorial policy, social environtment, and in certain cases, the technical problems.

\section{CONCLUSION}

Through the deep analysis of the research proposal background of the eighth semester students, the researcher found the model schematic structure and rhetorical problem 
of schematic structure by Swales CARS model and knowing kind of problem that found in the proposal background.

Besides, this study can be useful as reference to do the next research dealing with this research topic. The researcher hopes that this result of this study can acknowledge the next researchers and also help them to extend this study. So there will be many research findings dealing with this topic which can be useful for someone who wants to study rhetoric in writing.

\section{REFERENCES}

[1] Bryan Ricke, a thesis: Rhetorical Problem and Cinematic Solustions: The Visual Arguments of the "Obama Informecial. Clemson University, 2010.

[2] Fredrickson, K.M., \& Swales, J.M. Thirth editation Competition and discourse community: introductions from Nysvenka Studie. In B.L Gunarson, P. Linell, \& B. Nordberg, Text ang talk in professional context Sweden:ASLA, 2012

[3] Graduate School. How to Prepare Thesis Proposal, A guide for MPhil and PhD Students. The University of Hongkong, 2012.

[4] Kahn, J.H. Sample APA paper for students interested in learning $\quad$ APA th edition. (http://my.ilstu.edu/ jhkahn/APAsample.pdf. Accessed on 2nd April 2014).

[5] Fredrickson, K.M., \& Swales, J.M. Thirth editation, Academic writing for graduate students " essential task and skills ". In B.L Gunarson, P. Linell, \& B. Nordberg, Text ang talk in professional context Sweden:ASLA, 2012 research is quite useful to acknowledge students in writing a good research proposal background. By knowing the ideal 